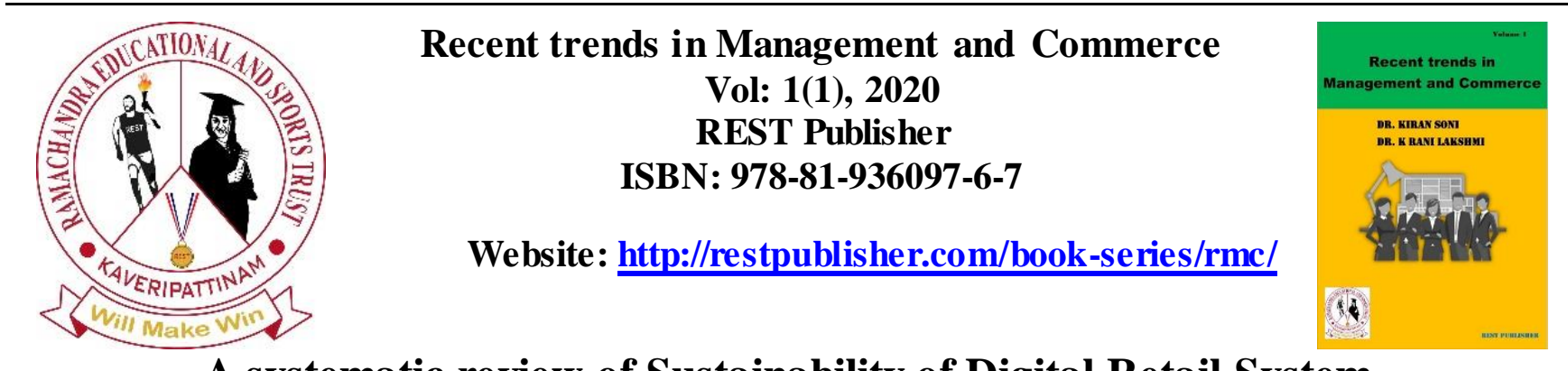

\title{
A systematic review of Sustainability of Digital Retail System
}

Kharde Yashomandira

Symbiosis Institute of Operations Management, Nashik, India

khardeyp@gmail.com

\begin{abstract}
The purpose of this paper is to understand the sustainability of the digital retail system. As the retail world has embraced digital to track consumers' needs right from their tweets to online retail, actual achievement for the seller is to motivate consumers to want what is the best for them, the seller, the society and the planet. In this study the authors have used systematic literature review (SLR) approach to identify the factors or variables from extant literature. The effect of these variables on the consumer behaviour was then analysed through exploratory factor analys is of the results of the responses to a structured questionnaire. The study finds out that the not just mere online shopping would be the retail of the fut ure, but a mix of both the physical and online experience, as the SLR output suggests. Shoppers at home should be able to visit virtual outlets and in-store shoppers should be able to access a cloud of information about products, so that the consumer experience will be more tailored, more continuous and more omnipresent. Like any study, this study has its own limitations. In this stud y, the authors have developed a model based on expert opinion. Though the sample size may not be enough to validate the model statistically, nevertheless, it can be regarded as a platform for further research study.
\end{abstract}

Keywords: systematic literature review; 3-D Printing; mobile payments; cloud computing.

\section{Introduction}

'Give consumers what they want.' It is an adage that has helped marketers well over the years, but is it fit for today's hyperconnected and high-tech digital age? Apparently, the obvious ans wer is 'Yes'. Fromour tweets to our online grocery practices, retail companies know more about us than ever before. Ubiquity, more choices, customized product and services, cheaper price, instant delivery, information availability, participation in auctions, ability to interact with electronic communities and no sales tax (in many countries) are the benefits of electronic commerce to the consumers (Turban, King, Viehland and Lee, 2006). Companies had to attract customers by providing them personalized services, changed their focus from product oriented marketing to demand oriented marketing and quality improvement, and have presently began laying emphasis on customer services, loyalty and profitability (Chang and Hong, 2011). With product search, price comparisons and reviews available in clearly understandable and easy-to-access formats online (Alreck and Settle, 2007), firms have started taking caution on "data" generated by third parties regarding their products and services. Consumers interact not just with the firm and other customers, but also with computers and related devices that mediate the digital commercial environment (Novak et. Al, 2000). Offering a radical difference from traditional modes of communication, consumers can also provide content which could often be outside the firm's control. Customers have started driving business by being the drivers for future strategies (Chang and Hong, 2011). Saving time and convenience in shopping has been the major motives behind online business (Constantinides, 2004). No one wants to pay more than they need to at the same time there is a barrier of 'time constraint'. Saving time is saving money. The personalisation of marketing messages, plus the benefit of e-commerce, could result in consumption boom. We see, we want it and then click and we buy it. It is a marketer's dream, but in a world of finite natural resources it could usher in an environmental nightmare. As per Google - A. T. Kearney study (2016), online sellers would need to grow by 5 times to serve the growing demands. Could automated technologies guide consumer buying decisions and what if smart data systems reduces the size of the data for them and effectively 'choice edited' their purchase s?. Through this study, one will discover that, giving consumers what they want is an easy win, but it is afflicted with sustainability challenges. Actual achievement lies in motivating consumers to want what best not only for them; but for all of us people, planet and profit-seekers. We get to see the advent of the digitalization of things with each product given a digital identity, every preference logged and every movement mapped. Information will intersect all areas of our lives. This will yield an opulent seam of data to be extracted and analysing and acting on those data patterns will be significant to retail success. With Amazon strategizing itself to overtake Wal-Mart as the world's biggest retailer, the question which needs to be addressed here is that can digital retail be more sustainable?. Experts in the retail sector say that the impact that information technology is expected to have on shopping over the next decade is immense. We will also probably see lots of novelplayers enter the game -small independents or online farmers' markets, peer-to-peer vendors as new technologies democratise the market and bring down impediments to entry for smaller players. When individuals do visit stores, the store is expected to communicate the emotional and rational benefits to the customer (Sonneck and Ott, 2005). What could all this mean for sustainability? People will be gifted with more opportunities to consume. By 2020 the store will come to the consumer, via whatever handheld device we are using then, with personalised offers to entice us to spend. There will be few physical, geographical or technological boundaries to making purchases. We certainly won't need to carry cash. We will just click for 
what we want. With adoption of digital retail and e-commerce platforms being made very easy with advents in technology by 2020 , the major challenges for retailers would be overcoming the need for "touch and feel", longer delivery times and delayed gratification of need (Google - A. T. Kearney study, 2016). Therefore, one of the biggest roles technology should play is to break down the barrier between the "real" and virtual" words (Sonneck and Ott, 2005). E-commerce should try to have use the various communication channels in a proactive manner. In this paper, we shall explore more about sustainability in digital retail and also the different variables affecting convenience in digital retail purchasing. We will use systematic literature review (SLR) approach.

\section{Literature Review}

We have used SLR approach proposed by Tranfield which is shown in the figure 1. The Identification for the require for a survey is to get it the victory of prevalent retail trade execution through innovative mediation and the components driving. In Arrangement of a proposition for an audit. We have looked into different articles distributed in trustworthy diaries other related diaries, books and magazines which is talked about on computerized retail and supportability in retail division. In creating an audit convention, the existing writing gives an opening point in characterizing computerized retail. Moreover, it makes a difference us highlight the driving and primary challenges within the operational and the conceptual space encompassing computerized retail and as semble set of operational measures that can be utilized to speak to it. In conducting our ponder and examination of different journals, we came over the most factors influencing comfort in computerized retail obtaining. In Recognizable proof of inquire about shows that there exist numerous depictions of advanced retail and its fundamental components along mind

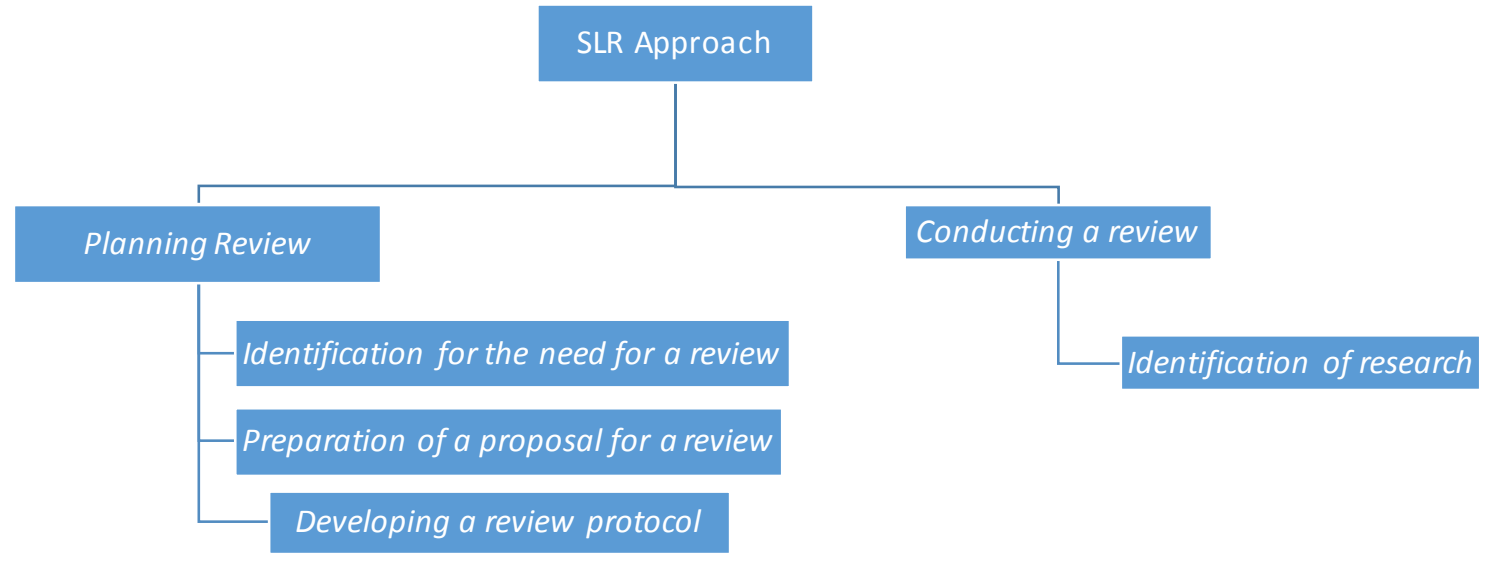

Figure 1: systematic literature review methodology by Tranfield et al 2003

A list of key variables has been identified after comprehensive literature review then the variables were short listed accord ing to their influence on Convenience in Digital Retail Purchasing (DRP). The final lis ts of eight variables were used to carry out the research.

Table 1: Key Variables Identified by SLR

\begin{tabular}{|c|c|c|}
\hline Authors, Year & Variables & Remark \\
\hline $\begin{array}{l}\text { Lyons et al. } \\
\text { (2008) }\end{array}$ & \multirow{2}{*}{$\begin{array}{l}\text { Click and } \\
\text { Collect }\end{array}$} & $\begin{array}{l}\text { Click and collect' overcome a few of the boundaries and may lead to a step-change } \\
\text { within the utilize of e-tailing as a shopping implies. }\end{array}$ \\
\hline $\begin{array}{l}\text { Steinfield et al. } \\
\quad(2002)\end{array}$ & & $\begin{array}{l}\text { conventional retailers are changing themselves into "click-and-collect" Internet- } \\
\text { enhanced organizations }\end{array}$ \\
\hline Porter (1985) & \multirow{3}{*}{$\begin{array}{l}\text { Dynamic } \\
\text { Clustering }\end{array}$} & $\begin{array}{l}\text { Clustering offers a substantial opportunity to decrease costs or upgrade separation in } \\
\text { any action within the esteem chain. }\end{array}$ \\
\hline $\begin{array}{l}\text { Porter (1998, p. } \\
\text { 208) }\end{array}$ & & $\begin{array}{l}\text { Part of clusters in competition requires inserting clusters in a broader and energetic } \\
\text { hypothesis of competition that includes both fetched and separation and both inactive } \\
\text { effectiveness and persistent change and development, which recognizes a world of } \\
\text { worldwide calculate and item markets. }\end{array}$ \\
\hline $\begin{array}{l}\text { Ellis on \&Glaes er } \\
(1997)\end{array}$ & & $\begin{array}{l}\text { In spite of significant inquire about on clusters, there's still much confusion } \\
\text { concerning the right conceptualization of a cluster. }\end{array}$ \\
\hline Mallat (2006) & \multirow{3}{*}{$\begin{array}{l}\text { Mobile } \\
\text { Payments }\end{array}$} & $\begin{array}{l}\text { Points of interest of portable installments incorporate time and put autonomy, } \\
\text { accessibility, conceivable outcomes for inaccessible buys, and line shirking }\end{array}$ \\
\hline Wiliped (2013) & & $\begin{array}{l}\text { Present day electronic commerce regularly employments more extensive extend of } \\
\text { advances such as mail, portable gadgets socialmedia, and phones as well }\end{array}$ \\
\hline Heijden (2002) & & Mobile phone is an effective mobile payment system. \\
\hline Fano (1998) & $\begin{array}{l}\text { Personal } \\
\text { digital } \\
\text { assistant }\end{array}$ & $\begin{array}{l}\text { A Individual computerized right hand (PDA) may be a GPS empowered operator } \\
\text { model that depends on information of a shopper's physical area to back the shopping } \\
\text { errand whereas shopping at a shopping center. }\end{array}$ \\
\hline $\begin{array}{l}\text { Subashini and } \\
\text { Kavitha (2010) }\end{array}$ & $\begin{array}{c}\text { Cloud } \\
\text { Computing }\end{array}$ & $\begin{array}{l}\text { Cloud computing may be a way to extend the capacity or include capabilities } \\
\text { powerfully without contributing in modern framework, preparing unused work force, } \\
\text { or permitting unused program. }\end{array}$ \\
\hline
\end{tabular}


Kharde. et.al / Recent trends in Management and Commerce Vol: 1(1), 2020: 62-66

\begin{tabular}{|c|c|c|}
\hline BNA (2009) & & $\begin{array}{l}\text { Analysts' assess that inside the following five a long time, the worldwide showcase } \\
\text { for cloud computing will develop to } \$ 95 \text { billion which } 12 \% \text { of the around the world } \\
\text { program showcase will move to the cloud in that period. To realize this colossal } \\
\text { potential, commerce must address the protection questions raised by this unused } \\
\text { computing show }\end{array}$ \\
\hline $\begin{array}{l}\text { Cong Wang et } \\
\text { al. (2009) }\end{array}$ & & $\begin{array}{l}\text { Cloud computing moves the application software and databases to the large data } \\
\text { centers. }\end{array}$ \\
\hline $\begin{array}{l}\text { Haeubl and } \\
\text { Trifts (1999) }\end{array}$ & \multirow{6}{*}{ Social Media } & $\begin{array}{l}\text { Social Media is an intuitively media which incorporates correspondence within the } \\
\text { trade of data, accessibility of data on request, reaction possibility, customization of } \\
\text { substance, and real-time input }\end{array}$ \\
\hline $\begin{array}{l}\text { Busby, Field, } \\
\text { Forth, (2010) }\end{array}$ & & $\begin{array}{l}\text { The advancement of innovation has driven to up to } 94 \text { per cent of showcasing } \\
\text { officials demonstrating that they anticipate to spend more on social media-based } \\
\text { showcasing }\end{array}$ \\
\hline Baker (2011) & & $\begin{array}{l}\text { He foremost broadly utilized social systems incorporate Facebook, MySpace, } \\
\text { LinkedIn, and numerous more. }\end{array}$ \\
\hline $\begin{array}{l}\text { Cuthbertson and } \\
\text { Piotrowicz } \\
\text { (2014) }\end{array}$ & & $\begin{array}{l}\text { Presents the comes about of center gather dialogs on the part of data innovation in } \\
\text { retail, modern commerce models, and long term part of conventional stores as e- } \\
\text { commerce propels. }\end{array}$ \\
\hline $\begin{array}{l}\text { Hoque and } \\
\text { Lohse (1999) }\end{array}$ & & $\begin{array}{l}\text { The guarantee of electronic commerce and online shopping will depend on client } \\
\text { interfacing and how people as sociated with computers. }\end{array}$ \\
\hline $\begin{array}{l}\text { www.encyclope } \\
\text { dia.com (2012) }\end{array}$ & & $\begin{array}{l}\text { E-commerce refers to the buying, selling, marketing, and servicing of products or } \\
\text { services over computer networks }\end{array}$ \\
\hline $\begin{array}{l}\text { Cohen, Sargeant } \\
\text { and Somers } \\
(2014) \\
\end{array}$ & \multirow{4}{*}{ 3-D printing } & $\begin{array}{l}\text { 3-D printers cannot as it were handle materials extending from titanium to human } \\
\text { cartilage but too deliver completely useful components, counting complex } \\
\text { instruments, batteries, transistors, and LEDs. }\end{array}$ \\
\hline $\begin{array}{l}\text { Barry Berman } \\
\quad(2012)\end{array}$ & & $\begin{array}{l}\text { 3-D printing has been compared to such troublesome innovations as computerized } \\
\text { books and music downloads that empower buyers to arrange their choices online, } \\
\text { allow firms to profitably serve little showcase sections and empower companies to } \\
\text { function with small or no unsold finished products inventory. }\end{array}$ \\
\hline $\begin{array}{l}\text { Petrovic et al. } \\
\text { (2011) }\end{array}$ & & In addition, $95 \%-98 \%$ of waste material can be recycled in 3 -D printing \\
\hline Berman (2002) & & $\begin{array}{l}\text { Other firms separated from Dell that utilize mass customization depend on deferred } \\
\text { separation generation frameworks that total the building of partially-constructed } \\
\text { items based on a customer's arrange prerequisites }\end{array}$ \\
\hline
\end{tabular}

Devices for Personal Digital Assistance (PDA) such as handheld mobile computing devices and barcode scanners have been gaining increasing importance in the retail industry, of late (Coughlan and Breslin, 2003). Improving the infrastructure for a global usage of the same, bringing down costs for service and maintenance of the same and a guarantee on the safety and usability of them, they provide an effective medium for communication in digital retail. Reports, even those made almost a decade ago, predicted 3-D printing to be a disruptive technology that could have a rapid and dis ruptive impact in economics. 3-D printing, or additive manufacturing, is already in use in the Consumer Packaged Goods sector, with 3-D-printed jewelry and toys being sold in online marketplaces (Brennan et. Al, 2013). In the near term, product designers in apparel, furniture and sporting goods sectors, to name a few can use 3-D printing to reduce prototyping time from weeks to minutes; in the longer term, it will open up mass customization opportunities. CPG manufacturers can closely follow the evolution of these technologies and experiment with means that can enable them connect with their customers. The click and drive model of commerce is gaining increasing support and gaining a particular contribution towards development of internet as a channel for retail. As stated by Colla and Lapoula(2011), all large retail companies defend their trade area, and avoid hav ing to deal opening new physical outlets or expanding existing ones.

Given the sheer number of mobile phones around today, it is no surprise that the notion has been gaining ground that the phone can also be effectively used as a transactional device (Heijden, 2002). Mobile payments have been suggested as a solution to facilitate micro-payments in electronic and mobile commerce, and to provide an alternative for the diminishing use of cash at POS (Begonha et al., 2002; Coursaris \& Hassanein, 2002). As stated by Mallat in 2006 the relative advantages of mobile payments include time and place independent payments, remote and ubiquitous access to payment services, and the possibility to avoid queuing and complement cash payments. This also avoids situations that demand queues, unexpected need for a payment, time pressure, and lack of cash or loose change. Development of these technologies can help improve electronic ticketing, purchases on vending machines and small value payments at POS. Porter, in 1985, stated that clustering can offer a tangible opportunity to reduce costs and enhance differentiation in any activity in the respective value chain. However, lack of clarity of the character and exact causes of the cluster benefits, and about relative benefits of various clusters lead to confusion and aversion to use the dynamic clustering (Karls son, 2007). If these problems are resolved, clustering can be used to effectively segment customers on a global scale, to promote digital retail as per the segment preferen ces. A unique characteristic of online shopping environments is that they allow for the implementation of very high degrees of interactivity (Gerald and Trifts, 2000). The way in which consumers search for product information and make purchase decisions is a function of the particular interactive tools available in an online shopping environment. The savvy consumers are using social media to research brands and companies before making a purchase digitally, and they talk about their findings openly in 
various online vehicles (Barnes, 2008). Small and Medium Businesses these days are increasingly tending to gain fast access to best business applications or drastically boost their infrastructure resources, at a very negligible cost (Subhashini and Kavitha, 2010). This promotes digital retail to a great extent. Most leading database vendors, such as Oracle, are adding cloud support for their services (Pearson, 2009). Therefore, more data is moving into the cloud, adding more manure for the promotion of digital retail. Privacy is sues are central to user concerns about adoption of cloud computing, and if technological mechanisms to allay users' concerns are introduced, cloud computing could have a great positive impact on digital retail.

\section{Results \& Discussion}

Impact of Personal Device Assistants: As much as 79\% of the respondents agreed that they used various PDAs, including their smartphones, to search for product options. They compared the specifications and prices of various options available to them, and used them for making a purchasing decision. These devices were of extreme attraction for the customers and usefulness for the retailers. As the customers could scan, track and bag their purchases as they shop, retailers could gain opportunities for improving the in-store experience for their visitors and potential customers. These devices are very logical in their application and can be the new touch points within the store. More than $72 \%$ of the respondents replied that they use $\mathrm{d}$ various smartphone applications for a better shopping experience online. They also gave an average score of 3.55 on a scale of 5, on their preference of using a smartphone or any other PDA system to make digital retail convenient for them. It is therefore an indication is that commerce is going to be on the fingertips of the customers, with the mediumbeing facilitated by these devices. However, this also has the disadvantage of the non-tech savvy customers abandoning the retailer. It also creates a situation in which the in-store retailing and marketing has become very competitive. The in-shelf decision to purchase a certain product can be disrupted by a wireless message from a competitor. Also, retailers who have smaller shops will find it difficult to invest in such technologies, preventing the reach of click and collect to the rural and under-developed parts of the world. Therefore, technology awareness among the customers and increased competition are the major hindrances to the sustainability of using personal device assistance devices to improve digital retail.

Impact of 3-D Printing: The technology of 3D printing has grown rapidly from being an additive manufacturing tool for the production of simple plastic prototype to being capable to produce fully functional requirements, such as mechanisms and batteries (Cohen et al., 2014). The main question on sustainability would be on the technicalchallenges, which include setting environmental parameters to prevent shape distortion, optimizing the speed of printing, and adjusting the properties of novel materials. Also tuning materials is quite a challenge.

Impact of click and collect: Respondents of the survey gave an average score of 4.14 on a scale of 5, indicating their preference towards the convenience of a click-and-collect system. Surprisingly, $97.16 \%$ of the respondents opined that shopping online has made their lives move faster and easier in terms of easiness regarding identification of the product to be purchased. Also, $96.22 \%$ of the respondents admitted that they search for a product online and explore its specifications and price, along with comparing them with their alternatives. While customers understand that there is easiness in gathering information from the web, the challenges come in complicated designs and layouts of the websites, internet penetration into the deeper reaches of the society and lack of systematic and standardized layouts in the e-tail stores.

Impact of mobile payments: Respondents of the survey gave an average score of 3.84 on a scale of 5, indicating their preference towards the payment of bills on their smartphones. 83\% of them already use their smartphones to pay for the purchase a product online, or to pay their bills. This is when over $90 \%$ of the respondents already agree that the mobile payment systems have made the payment processes easier, faster and hassle-free. An equal number of respondents state that they consider payment through smart phones as a means to collect their cashbacks and reward points, instead of physical membership and loyalty cards. They have also realized that the mobile payment methods are all safe, secure and reliable, unlike the prevous notions regarding the same. The perceived risk, regarding the privacy and data security at the customer's end, and the high costs involved in the setting up of the necessary infrastructure at the lower strata of the securities have been the major questions on the sustainability of the service.

Impact of dynamic clusters: Segmentation of consumers is becoming increasingly challenging these days with mixed attributes and missing data. With the same product belonging to multiple clusters and certain data not being relevant for clustering, the typical fixed-length clustering cannot be employed (Ayuyev et. al, 2012). Several Numerical experiments have been conducted for the algorithm of dynamic clustering, demonstrating a stable (10-44\%) increase in the performance quality of clustering of continuous -type data and a slight (3-7\%) decrease in the performance quality of clustering of category-type data (these figures have been obtained in comparis on with the algorithmof static clustering). Dynamic clustering can influence competition among retailers to a great extent. Innovation in retailing process would be the biggest change the dynamic clustering would bring in, by increasing competition among the retailers. Associated changes would also be reflected in the product lifecycle, as innovation and competition would create a competitive battle among themselves. New businesses would be simulated in this process, fostering the product lifecycle and promoting sustainability to the industry life spans. Therefore, the hypotheses.

Impact of Social media: The respondents gave an average score of 3.1 on a scale of 5, on their tendency to rely on various online social media platforms to make their purchasing decisions. $72.6 \%$ of the respondents provided reviews on the products purchased, or took the feedback of others to exercise their purchasing behaviour. These platforms could be the website of the company, or various social media websites. Also, over $60 \%$ of the respondents relied on these media to gain awareness on various offers on the products of their choice. From the retailer's point of view, knowing the customer is a key aspect for successful retailing. Social media platforms provide more opportunities to gather information about customers, and also to interact with the customers in a more effective way. Also, if the retailer can track what a customer wishes to buy and where, then more targeted marketing can be introduced. The major questions on the sustainability include the easiness of usage of social media for the less privileged and educated strata of the society, and the limited access to internet in remote areas. 
Impact of cloud computing: As digital retail has entered the era of Big Data Analytics and customer-centric mode of servicing, a huge amount of data is generated which needs to be mined appropriately to process and manage (Verma and Singh, 2017). To provide a platform for these mining operations, which are beyond the capabilities of traditional data processing software, cloud framework is one that needs basic investment in. With options such as parallel Apriorialgorithms being enabled to process huge data sets being developed to ad apt to cloud platforms (Wang and Li, 2013) cloud computing can be viewed as a sustainable platform for digital retail to store and process its huge datasets in. Hadoop-based cloud infrastructure can provide partial failure support, scaling, fault tolerance, real time processing, etc., as should be expected of any big data analytics system(Verma and Singh, 2017). The basic questions for sustainability in this case are data security and authenticity. Since the SaaS Cloud Demand platform has been taken in by various private cloud management partners, trustworthiness of the data is also in question (Cong Wang et al., 2009). If the cloud software providers can come up with sustainable solutions for these is sues, cloud computing can enhance convenience in DRP in the longer years to come.

\section{Conclusion}

In this study, systematic literature review (SLR) approach is used to identify the factors or variables from extant literature. The effect of these variables on the consumer behaviour was then analysed through exploratory factor analysis of the results of the responses to a structured questionnaire. The study finds out that the not just mere online shopping would be the retail of the future, but a mix of both the physical and online experience, as the SLR output sugg ests. Shoppers at home should be able to visit virtual outlets and in-store shoppers should be able to access a cloud of information about products, so that the consumer experience will be more tailored, more continuous and more omnipresent. Like any study, this study has its own limitations. In this study, the authors have developed a model based on expert opinion. Though the sample size may not be enough to validate the model statistically, nevertheless, it can be regarded as a platform for further research study.

\section{References}

[1]. Gladstone, Julia Alpert. "Exploring the Role of Digital Currency in the Retail Payments System." New Eng. L. Rev. 31 (1996): 1193.

[2]. Wandhöfer, R., 2017. The future of digital retail payments in Europe: A role for central bank issued crypto cash. Journal of Payments Strategy \& Systems, 11(3), pp.1750-1806.

[3]. Dubey, Rameshwar, and Tripti Singh. "Understanding complex relationship among JIT, lean behaviour, TQM and their antecedents using interpretive structural modelling and fuzzy MICMAC analysis." The TQM Journal (2015).

[4]. Wang, Jian, Yan Zhao, Shuo Jiang, and Jiajin Le. "Providing privacy preserving in cloud computing." In 3 rd International Conference on Human System Interaction, pp. 472-475. IEEE, 2010.

[5]. Verma, Neha, and Jatinder Singh. "An intelligent approach to Big Data analytics for sustainable retail environment using Apriori-MapReduce framework." Industrial Management \& Data Systems (2017).

[6]. Kiraz, Mehmet Sabır. "A comprehensive meta-analysis of cryptographic security mechanisms for cloud computing." Journal of Ambient Intelligence and Humanized Computing 7, no. 5 (2016): 731-760.

[7]. Chang, Wei-Lun, and Yu-Ting Hong. "A Mixture Model to Estimate Customer Value for E-Services." In Proceedings of the 2009 Academy of Marketing Science (AMS) Annual Conference, pp. 99-103. Springer, Cham, 2015.

[8]. Al-Hujran, Omar, Enas M. Al-Lozi, Mutaz M. Al-Debei, and Mahmoud Maqableh. "Challenges of cloud computing adoption from the TOE framework pers pective." International Journal of E-Business Research (IJEBR) 14, no. 3 (2018): 77-94.

[9]. Mathur, Amit K., Yu-Hui Chang, D. Eric Steidley, Raymond L. Heilman, Nabil Wasif, David Etzioni, Kunam S. Reddy, and Adyr A. Moss. "Factors associated with adverse outcomes from cardiovascular events in the kidney transplant population: an analysis of national discharge data, hospital characteristics, and process measures." BMC nephrology 20 , no. 1 (2019): 190.

[10]. Van der Heijden, Beatrice. "Prerequisites to guarantee life-long employability." Personnel review (2002).

[11]. Ayuyev, V. V., A. Thura, N. N. Hlaing, and M. B. Loginova. "The quick dynamic clustering method for mixed-type data." Automation and Remote Control 73, no. 12 (2012): 2083-2088.

[12]. Wang, Jiaqi, Haiyun Wu, Miao Song, Fengqin Li, Jianghui Zhu, Meili Xi, Xin Wang et al. "Prev alence and quantitative detection of Salmonella in retail raw chicken in Shaanxi, China." Journal of food protection 76, no. 11 (2013): 19581962.

[13]. Weinstock, Peter, Roberta Rehder, Sanjay P. Prabhu, Peter W. Forbes, Christopher J. Roussin, and Alan R. Cohe n. "Creation of a novel simulator for minimally invasive neurosurgery: fusion of 3D printing and special effects." Journal of Neurosurgery: Pediatrics 20, no. 1 (2017): 1-9.

[14]. Coursaris, Constantions, and Khaled Hassanein. "Understanding m-commerce: a consumer-centric model." Quarterly journal of electronic commerce 3 (2002): 247-272.

[15]. Möller, Kristian. "The marketing mix revisited: Towards the 21st century marketing by E. Constantinides." (2006): 439-450.

[16]. Begonha, Duarte Bacelar, Alexandre Hoffmann, and Paul Melin. "M-payments: Hang up, try again." Credit Card Management 15, no. 10 (2002): 40-40.

[17]. Kolen, Michael J., and Robert L. Brennan. Test equating: Methods and practices. Springer Science \& Business Media, 2013. 